\title{
Embryonic expression of the human MID1 gene and its mutations in Opitz syndrome
}

\author{
L Pinson, J Augé, S Audollent, G Mattéi, H Etchevers, N Gigarel, F Razavi, D Lacombe, S Odent, \\ M Le Merrer, J Amiel, A Munnich, G Meroni, S Lyonnet, M Vekemans, T Attié-Bitach
}

J Med Genet 2004;41:381-386. doi: 10.1136/jimg.2003.014829

$\mathrm{O}$ pitz syndrome (G/BBB syndrome, MIM145410 and MIM300000) is a midline congenital malformation characterised by hypertelorism, hypospadias and oesophagolaryngotracheal defects leading to swallowing difficulties and a hoarse cry. ${ }^{1}$ Additional defects include cleft lip with or without cleft palate, imperforate anus, anomalies of the central nervous system (including corpus callosum agenesis or vermis agenesis and hypoplasia), ${ }^{2}$ congenital heart defects (atrial and ventricular septal defects, patent ductus arteriosus and coarctation of the aorta), ${ }^{3}$ and developmental delay in two thirds of patients. This condition is genetically heterogeneous with an X-linked recessive form mapped to Xp22.3 and at least one autosomal dominant form mapped to chromosome 22q1 1.2. ${ }^{4}$ Also, several patients with an autosomal Opitz syndrome have been reported with a 22q11 deletion. ${ }^{5}{ }^{6}$ Recently, mutations in MID1, a member of the B-box protein family have been identified in the X-linked form of the disease $\mathrm{e}^{7}$ but the gene for the autosomal dominant form on 22q11 remains unknown.

MIDI encodes a protein belonging to a novel subclass of RING, B-box, Coiled-Coil proteins characterised by a fibronectin type III motif and a C-terminal domain. Although the function of MIDl remains unknown, recent experiments have demonstrated that MIDI is a microtubule associated protein, belonging to a large multiprotein complex ${ }^{8} 9$ involved in ubiquitination through microtubules. ${ }^{10}$ MIDl association with microtubules is regulated by dynamic phosphorylation involving MAP kinase and protein phosphatase $2 \mathrm{~A}$ that is targeted specifically to MIDl by a regulatory $\alpha 4$ subunit.

Here, we report on six MIDI mutations in a cohort of 14 patients with Opitz syndrome and on heart and hindbrain expression of MIDI during early human development using mRNA in situ hybridisation. In addition, we investigate the contribution of chromosome X-inactivation studies to identify the X-linked form of the disease.

\section{METHODS}

Patients

A total of 14 cases were included in the study, namely six familial forms consistent with X-linked inheritance and eight isolated cases ( 11 males and 3 severely affected females). Minimal inclusion criteria were: three major signs (hypertelorism, hypospadias in males or genital abnormalities in females, oesophagolaryngotracheal defects) or two major and at least two minor signs (cleft lip with or without cleft palate, anal malformation, congenital heart defects, central nervous system malformation, and limb or skeletal abnormalities). Patients were tested for 22q11 deletion using fluorescent in situ hybridisation. Magnetic resonance imaging of the brain was performed in most cases. Table 1 summarises the clinical findings and molecular data of patients with a known MIDI mutation.

Patient 1 belongs to a large family (fig l, family 1 ) with several affected individuals. The proband had hypertelorism, a broad nasal bridge, swallowing difficulties, laryngeal cleft,

\section{Key points}

- Opitz syndrome (G/BBB syndrome, MIM145410, and MIM300000) is a midline congenital malformation characterised by hypertelorism, hypospadias and oesophagolaryngotracheal defects leading to swallowing difficulties and hoarse voice. This condition is genetically heterogeneous with an X-linked recessive form mapped to Xp22.3 and at least one autosomal dominant form mapped to chromosome 22q11.2. Recently, mutations in MIDI have been identified in the X-linked form of the disease but the gene for the autosomal dominant form on $22 q 11$ remains unknown.

- Here we report on MIDI mutations screening in a series of 14 patients with Opitz syndrome and the MIDI expression pattern in human embryos using hybridisation in situ. Finally, we investigated the contribution of chromosome $\mathrm{X}$-inactivation studies to identify the X-linked form of the disease.

- Six MID1 mutations were identified in our series. All mutations were novel except the R495X mutation previously reported in three unrelated patients. We report heart and hindbrain expression of MIDI during early human development. Obligate carrier mothers showed a random pattern of X-inactivation.

- Vermis hypoplasia or agenesis was frequently present $(4 / 9)$ in patients with MIDI mutation. The heart and hindbrain expression of MIDI during early human development further supports the view that heart defects and vermis hypoplasia or agenesis are features to be included in the malformative spectrum of the syndrome. Finally, the study of X-inactivation pattern in women does not help discrimination between $\mathrm{X}$-linked and autosomal forms of the disease.

and hypospadias (fig 1A). He was not developmentally delayed. His mother only had hypertelorism and his brother had hypertelorism, swallowing difficulties, and posterior urethral valves.

Patient 2a (fig 1, family 2) had hypertelorism, anteverted nostrils, laryngeal diastema, bilateral cleft lip, hypospadias and developmental delay. Magnetic resonance imaging showed vermis hypoplasia. His half brother (2b) had hypertelorism, severe pharyngotracheal fistula, and hypospadias. In addition, he had a unilateral cleft lip with a broad nasal bridge and a widow's peak, a flat philtrum, and

Abbreviation: DHPLC, denaturing high performance liquid chromatography 
Table 1 Clinical and molecular data of Opitz syndrome patients with a known MID1 mutation

\begin{tabular}{|c|c|c|c|c|c|c|c|c|c|c|c|c|c|}
\hline \multirow[b]{4}{*}{ Main features } & \multicolumn{13}{|c|}{ Our series familial (F) and sporadic (S) cases } \\
\hline & \multicolumn{2}{|l|}{ Family 1} & \multicolumn{2}{|l|}{ Family 2} & \multirow{3}{*}{$\frac{\text { Patient } 3}{\text { (F) }}$} & \multirow{3}{*}{$\frac{\text { Patient } 4}{\text { (F) }}$} & \multicolumn{2}{|l|}{ Family 6} & \multirow{3}{*}{$\frac{\text { Patient } 9}{\text { (S) }}$} & \multirow{3}{*}{$\frac{\text { Total }}{19}$} & \multirow{2}{*}{\multicolumn{2}{|c|}{$\begin{array}{l}\text { Previous } \\
\text { studies }^{11}\end{array}$}} & \multirow{3}{*}{$\begin{array}{l}\text { Tota } \\
\% \\
/ 37\end{array}$} \\
\hline & \multicolumn{2}{|l|}{ (F) } & \multicolumn{2}{|l|}{ (F) } & & & \multicolumn{2}{|l|}{ (F) } & & & & & \\
\hline & proband & brother & proband & brother & & & proband & brother & & & $/ 28$ & $\%$ & \\
\hline $\begin{array}{l}\text { Hypertelorism or telecantus } \\
\text { Hypospadias } \\
\text { Urogenital abnormalities } \\
\text { Oesophagolaryngotracheal } \\
\text { anomalies } \\
\text { Cleft lip or palate } \\
\text { Ear abnormalities } \\
\text { Anteverted nostrils } \\
\text { Heart defects } \\
\text { Anal abnormalities } \\
\text { Brain anomalies } \\
\text { Developmental delay } \\
\text { MID1 mutation }\end{array}$ & $\begin{array}{l}+ \\
+ \\
+ \\
- \\
+ \\
- \\
- \\
- \\
- \\
- \\
\text { G452S }\end{array}$ & $\begin{array}{l}+ \\
- \\
+ \\
+^{*} \\
- \\
+ \\
- \\
- \\
- \\
- \\
-\end{array}$ & $\begin{array}{l}+ \\
+ \\
+ \\
+ \\
+ \\
+ \\
- \\
- \\
+ \\
+ \\
\text { R277X }\end{array}$ & $\begin{array}{l}+ \\
+ \\
+ \\
+ \\
+ \\
- \\
- \\
- \\
? \\
+\end{array}$ & $\begin{array}{l}+ \\
+ \\
+ \\
- \\
- \\
+ \\
+ \\
- \\
- \\
+ \\
\text { a.1285+2 } \\
\text { delGAGT }\end{array}$ & $\begin{array}{l}- \\
+ \\
+ \\
- \\
+ \\
+\ddagger \\
- \\
1447- \\
1448 \\
\text { insAACA }\end{array}$ & $\begin{array}{l}+ \\
+ \\
+^{*} \\
+ \\
+ \\
+ \\
- \\
+ \\
+† \\
+ \\
\text { R495X }\end{array}$ & $\begin{array}{l}+ \\
+ \\
++^{*} \\
- \\
? \\
+ \\
+ \\
- \\
+\S \\
+\end{array}$ & $\begin{array}{l}+ \\
+ \\
+ \\
+ \\
+ \\
+ \\
- \\
- \\
- \\
? \\
- \\
403-411 \\
\text { del }\end{array}$ & $\begin{array}{l}3 \\
7 \\
5 \\
2 \\
2 \\
4 \\
5\end{array}$ & $\begin{array}{l}28 \\
25 \\
21 \\
15 \\
11 \\
11 \\
9 \\
8 \\
6 \\
14\end{array}$ & $\begin{array}{l}100 \\
89 \\
75 \\
54 \\
39 \\
39 \\
32 \\
28 \\
21 \\
50\end{array}$ & $\begin{array}{l}100 \\
89 \\
78 \\
49 \\
48 \\
43 \\
30 \\
27 \\
27 \\
51\end{array}$ \\
\hline $\begin{array}{l}\text { *patients presenting with swo } \\
\text { tvermis hypoplasia } \\
\text { tinferior vermis agenesis } \\
\text { §vermis and posterior corpus }\end{array}$ & allosum hyp & ulties but & no anatomi & cal defects & & & & & & & & & \\
\hline
\end{tabular}

low set ears. He required special education. Their mother had a normal phenotype.

Patient 3 had a prominent forehead, hypertelorism, anteverted nostrils, and a widow's peak (fig 1, family 3). He also had swallowing difficulties with laryngeal cleft and severe hypospadias with micropenis, umbilical and inguinal hernia, and mild mental retardation. No brain investigation was available. His mother had hypertelorism and required surgery for a short nose and a broad nasal bridge.
Patient 4 (fig 1, family 4) was the first child of healthy parents. He had hypertelorism, papillar coloboma, anteverted nostrils, low set ears, swallowing difficulties with laryngeal diastema, and nasal voice, hypospadias, imperforate anus, and bilateral ureteral reflux (fig $1 \mathrm{~B}$ ). Magnetic resonance imaging showed inferior vermis agenesis but no developmental delay was noted. His family history was suggestive of Opitz syndrome segregating over three generations. Indeed, his maternal grandmother, his mother (fig 1B), his maternal

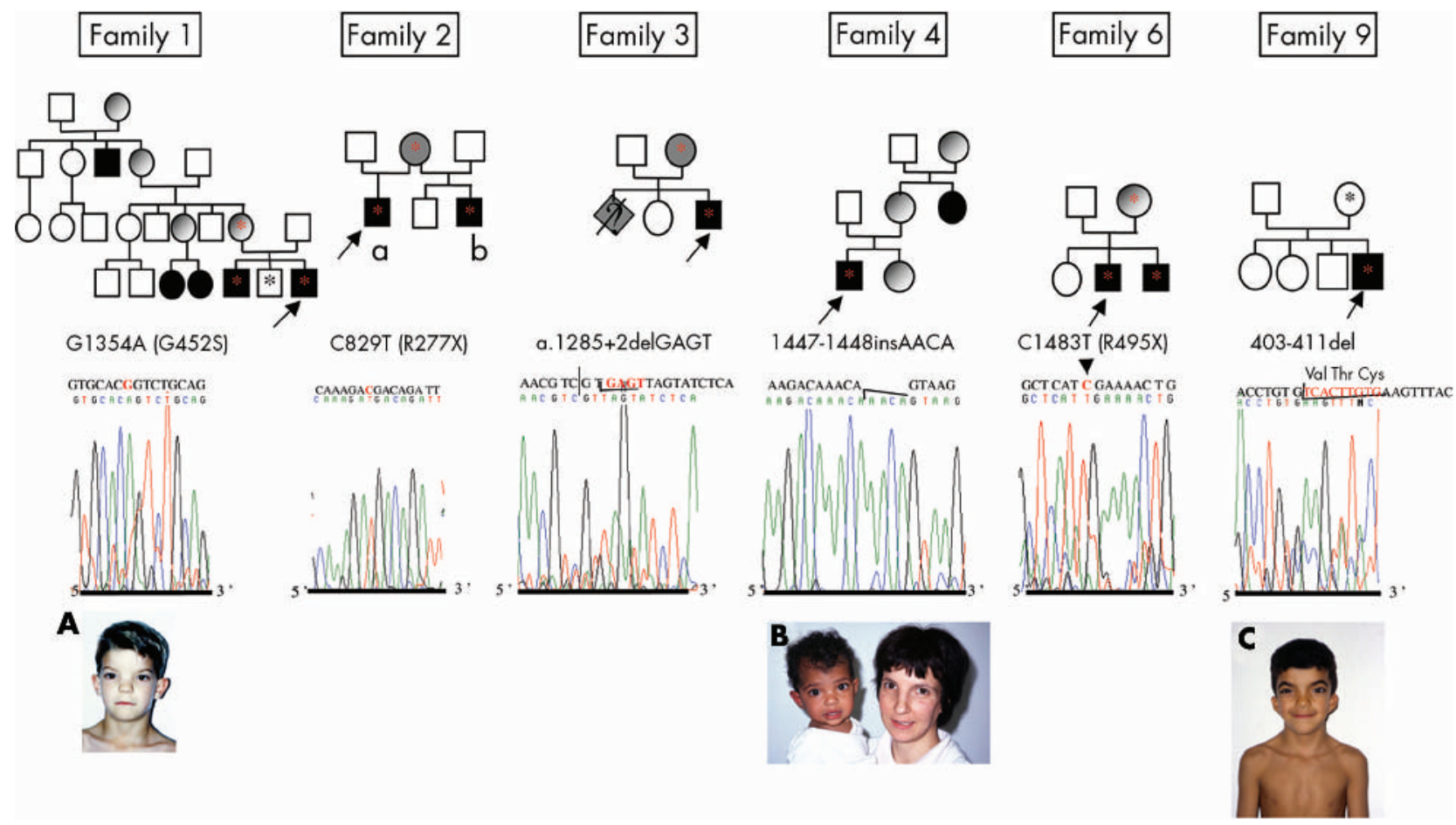

Figure 1 Pedigree and sequence of probands with a MIDI mutation. Photographs of three probands $(\mathrm{A}, \mathrm{B}, \mathrm{C})($ Reproduced with parents' permission) and a mother (B) (Reproduced with mother's permission). Pedigree and mutations in the X-linked locus. In family 3 , the proband brother died during pregnancy and had bilateral cleft lip and palate. The DNA sequence chromatograms are shown below the normal nucleotide sequence. * Patients for whom molecular analysis was performed, carrying the mutation (red) or not (black). 
aunt, and his sister had hypertelorism. His sister also had an anal malformation.

Patient 6 and his young affected brother had microcephaly, vermis hypoplasia, hypertelorism, swallowing difficulties in early childhood, and hypospadias (fig 1, family 6). He also had a broad nasal bridge, a single central incisor, a cleft lip and palate, and growth retardation. Psychomotor delay with severe speech delay was present at $4 \frac{1}{2}$ years of age. The proband's brother had a ventricular septal defect, a rectourethral fistula, a wide anterior fontanelle and hypoplasia of the posterior part of the corpus callosum. His sister had hypertelorism and anal anteposition.

Patient 9 had hypertelorism, low set posteriorly rotated ears, swallowing difficulties in childhood, hypospadias, and bilateral ureteral reflux (fig $1 C$ ). He had normal intelligence at 10 years of age and no brain investigation was performed.

\section{MID 1 mutation screening}

Genomic DNA was extracted from peripheral blood leucocytes using standard procedures. The nine exons of the MIDI gene were PCR amplified using 12 MIDI-specific primer pairs as reported by Gaudenz et $\mathrm{al}^{12}$ except for exon 5 which was amplified using another reverse primer $\left(5^{\prime}\right.$-aagacaatacctgtaaggtaatc). Denaturing high performance liquid chromatography (DHPLC) was used to detect nucleotide variants. We determined the optimal analysis conditions, as previously reported $^{13}$ (mobile phase temperatures and acetonitrile gradients are available on request). PCR products demonstrating DHPLC variants were sequenced on both strands using the big dye terminator cycle sequencing kit (Applied Biosystems) and analysed on an ABI 377A automated sequencer. For X-inactivation studies, we analysed the methylation pattern at the human androgen receptor locus as previously described by Hickey et al. ${ }^{14}$

\section{MID 1 in situ hybridisation}

Human embryos were collected from terminated pregnancies in agreement with French law (94-654 of July 29, 1994) and the National Ethics Committee recommendations (No 1 of May 22, 1984).

Tissues were fixed in 4\% paraformaldehyde, embedded in paraffin blocks and sectioned at $5 \mu \mathrm{m}$. Exon 9 primers were selected for PCR amplification (F: ggcttctatcgcttttatga, R: cacaggcttcatgagtgtaa). A T7 promoter sequence extension (taatacgactcactatagggaga) was added at the 5' end of each primer. T7F/R and F/T7R primers allowed the amplification of sense and antisense templates. Riboprobes were labelled using T7 polymerase in the presence of $\alpha\left[{ }^{35}\right.$ S JUTP (1200 Ci/ mmol; NEN). Riboprobes were then purified on Sephadex G50 columns. Hybridisation and posthybridisation washes were carried out according to standard protocols. ${ }^{15}$ Slides were dehydrated, exposed to BIOMAX MR X-ray films (Amersham) for 3 days, dipped in Kodak NTB2 emulsion for 3 weeks at $+4^{\circ} \mathrm{C}$, then developed and counterstained with toluidine blue, coverslipped with Eukitt, and analysed under dark and bright field illumination. No hybridisation signal was detected with the $\alpha\left[{ }^{35} \mathrm{~S}\right]$-labelled sense probe (fig $3 \mathrm{Y}$ and not shown), confirming that the expression pattern obtained with the $\alpha\left[{ }^{35} \mathrm{~S}\right]$-labelled antisense probe was specific.

\section{RESULTS}

Denaturing high performance liquid chromatography and direct sequencing analysis of the nine exons of the MIDl gene detected six mutant genotypes among our 14 unrelated Opitz syndrome patients (figs 1 and 2). In patient 1, a G1354A missense mutation in exon 7 changed a glycine into a serine (G452S) in the FNIII domain of the protein, the function of which remains unknown (fig 2). The mutation was also detected in the mildly symptomatic mother and her two affected sons but not in the unaffected brother. In patient 2 , a C829T nonsense mutation (R277X) in exon 3 truncated the C-terminal domain, the FNIII and the coiled-coil domains of the protein, the latter domain mediating homodimerisation. ${ }^{16}{ }^{17}$ The mutation was also observed in his mother and his affected half brother but not in his unaffected brother. In patient 3 and his mildly affected mother, we identified a $4 \mathrm{bp}$ deletion in the splice donor site of intron 6 (a.1285+2delGAGT), which was expected to result in either an unstable transcript or a significant alteration at the $\mathrm{C}$ terminal end of the protein because of aberrant splicing. Unfortunately, no cell line from patient 3 was available to test this hypothesis by reverse transcription experiments. Patient 4 carried a 4 bp insertion in exon 7 (1447-1448 insAACA), predicting a premature stop codon five amino acids downstream, truncating the MIDl protein and lacking the $\mathrm{C}$ terminal domain. No DNA was available for other family members. In patient 6, a C1483T nonsense mutation (R495X) truncated the C-terminal domain of the MIDl protein

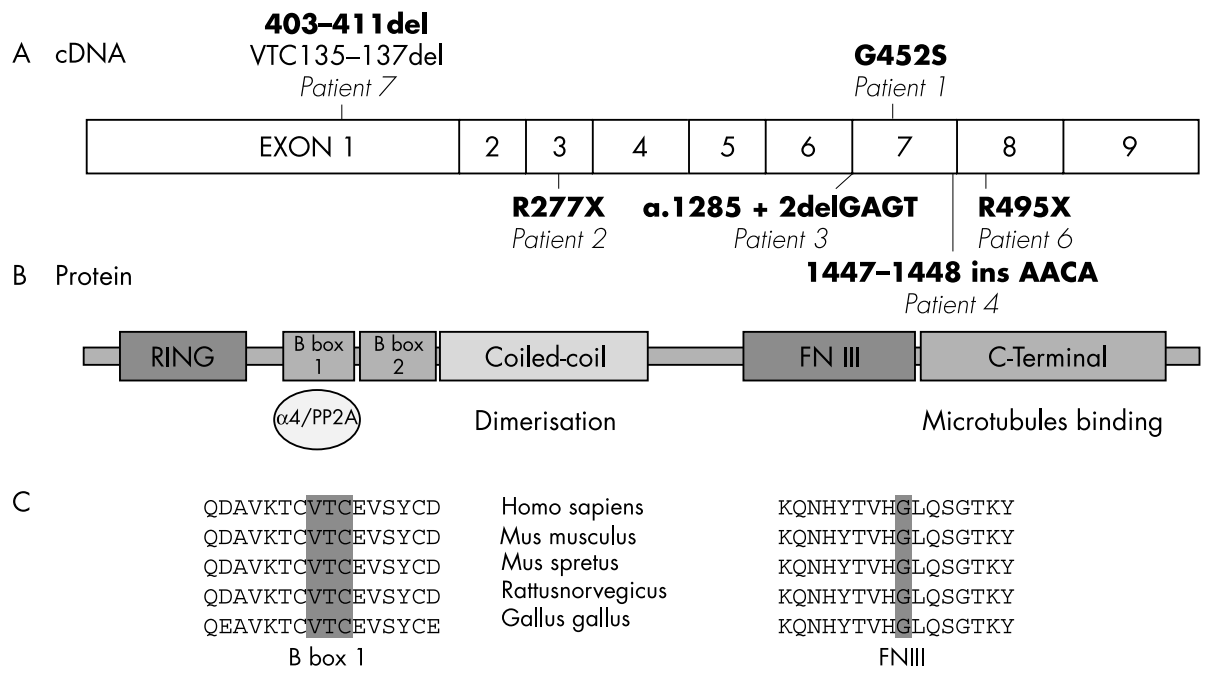

Figure 2 MID1 mutations identified in our series. Schematic representation of MIDI CDNA (A) and protein with respect to the different functional domains (B). Mutations identified in our series are indicated. C: MIDI alignment by CLUSTAL W* in five species is shown for the two domains where the three amino acid deletion (B-Box 1) and the missense mutation are located (FNIII). The concerned amino acids are conserved in all species. 

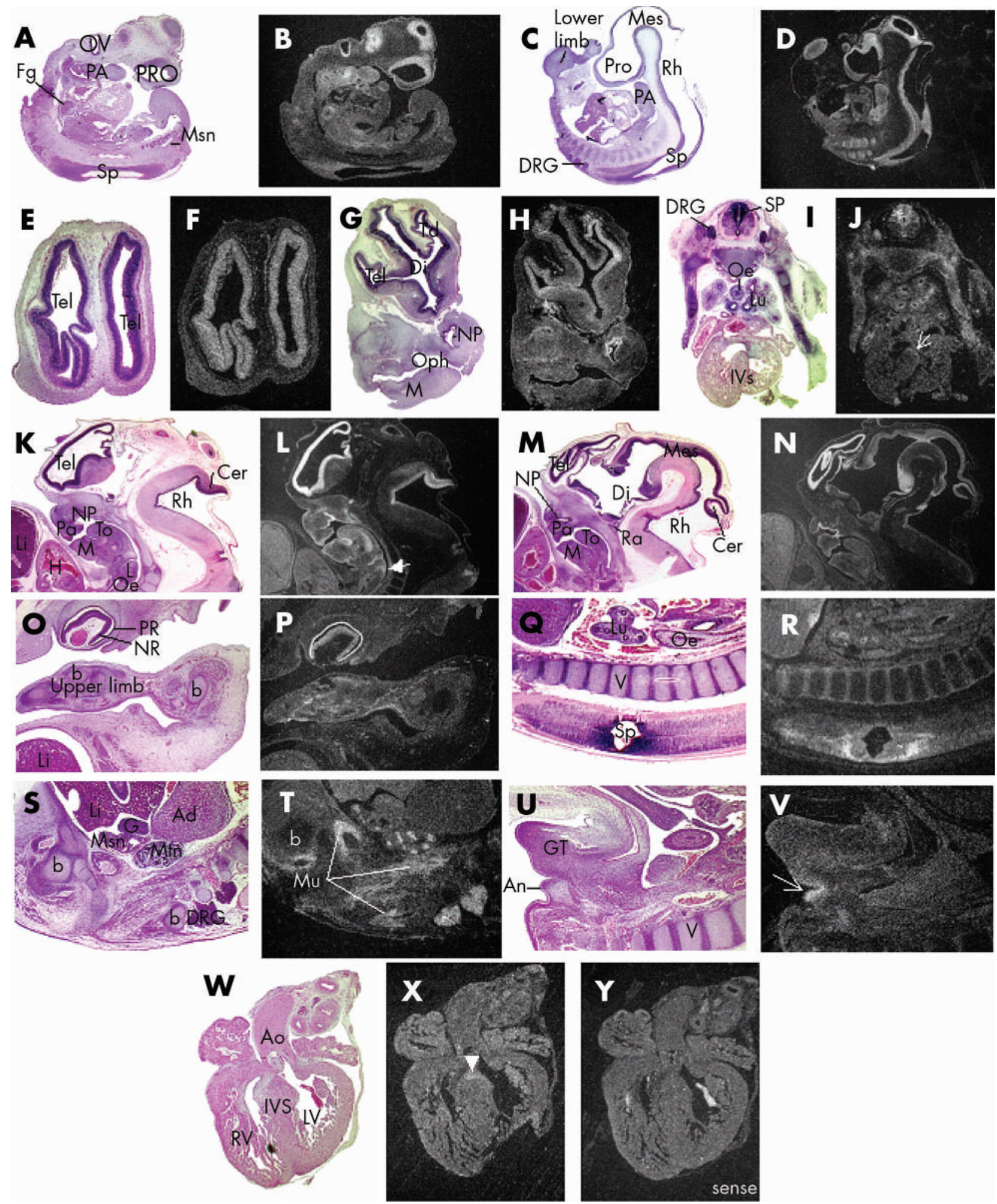

Figure 3 MIDI expression in human embryos. MIDI expression by in situ hybridisation on human embryos (A-V) and fetal tissues (W-Y). A, C, E, G, $I, K, M, O, Q, S, U$, and $W$ are bright field illuminations of slides stained with haematoxylin, eosin, and safran adjacent to the ones presented for in situ hybridisation studies in dark field illumination (B, D F, H, J, L, N, P, R, T, V , X, Y). (A-D) Sagittal and parasagittal sections of 5 week old human embryos showing MIDI expression in prosencephalon (Pro), mesencephalon (Mes), rhombencephalon (Rh), spinal cord (Sp), dorsal root ganglia (DRG), otic vesicle (OV), pharyngeal arches (PA), foregut (Fg), mesonephros (Msn), and limb buds. (E-J) Transverse sections of 6 week old human embryo through the head (E-H) showing the expression in telencephalic vesicle (Tel), and in nasal (NP) and oropharynx epithelia (Oph). I and J are sections through the body at the thoracic level, showing the MIDI transcripts in spinal cord, dorsal root ganglia, epithelium of lung (Lu), and oesophagus (Oe). Very localised MIDI expression is observed at the top of the interventricular septum (IVS, arrow). (K-V): sagittal and parasagittal sections of 7 week old human embryo. In the head, (K-N), MIDI is strongly expressed in telencephalon, cerebellum bud (Cer), nasopharyngeal (NP) epithelia, and at the oesophagolaryngeal junction (arrow). O and P show MIDI expression in limb mesenchyme but not in developing bones (b) and in neural retina (NR). Note the false positive signal given by the pigmented retina (PR). Q and R show the MIDI expression in the spinal cord and the respiratory and digestive tract epithelia. S, T: strong MIDI expression is observed in epithelia derivatives of developing kidney (Mtn) and in muscular cells of proximal limbs (Mu). No expression is observed in adrenal glands (Ad), gonads (G), or liver (Li). U, V: MIDI is expressed in the anal folds (arrow, An) and in the genital tubercle (GT). (W-Y) MIDI expression at the tip of the interventricular septum is clearly observed (arrowhead) in an 8.5 week old heart as compared to the control hybridised adjacent section (Y). Ao, aorta; H, Heart; L, larynx; LV, left ventricle; $M$, mandible; Oe, oesophagus; Pa, palate; Ra, Rathke pouch; RV, right ventricle; To, tongue. 
involved in microtubule binding. Previous immunohistochemical experiments have shown that a MIDl protein carrying a mutation in the C-terminal domain does not associate with microtubules but rather forms cytoplasmic clots. ${ }^{18}$ Restriction analysis using the Taq 1 restriction enzyme detected the same mutation in his mother and his young brother. Finally, a 9 bp in frame deletion in patient 9 (403$41 \mathrm{ldel}$ ) abolished three conserved amino acids (valine, threonine, and cysteine) in the B-boxl domain (fig 2a) which interacts specifically with phosphatase $2 \mathrm{~A}$ through its $\alpha 4$ subunit. $^{10}$ These findings suggest an important role of these three amino acids for binding the $\alpha 4$ subunit to the MIDl protein. The asymptomatic mother did not carry the mutation, which therefore occurred de novo.

These nucleotide changes were not observed in 100 control chromosomes. Sequencing of two additional abnormal DHPLC patterns revealed conservative polymorphisms in exon 3 and 8 (G287G and S410S) in patients 4 and 12 respectively.

$\mathrm{X}$-inactivation studies revealed a skewed inactivation pattern (91\%:9\%) in a severely affected female with Opitz syndrome, who had hypertelorism, laryngeal diastema, oesophageal atresia, anterior placement of the anus, and developmental delay. However, we failed to detect any MIDI mutation in this patient. The other two affected females with Opitz syndrome and the three obligate carrier mothers showed a random X-inactivation pattern.

MIDI expression pattern was studied during early human development using in situ hybridisation on human embryo sections at Carnegie stages 14 (that is, day 32), 15 (day 33), 18 (day 44), and 19 (day 47) and at 8.5 weeks of development (fig 3). At day 32, MIDI was strongly expressed in the central nervous system, from the prosencephalon (except its most anterior part) to the spinal cord. MIDI expression was also observed in the ventral part of the otic vesicle, the pharyngeal arches, the gastrointestinal tract, and the mesonephros (fig 3A, B). The same expression pattern was observed at day 34 in the central nervous system. In addition, a signal was observed in dorsal root ganglia, sclerotomes and limb buds (fig 3C, D). At day 44, MIDI expression was observed in telencephalic vesicles (fig 3E, F) but not in the medial diencephalon (fig 3G, H). Also, it was expressed in the respiratory and digestive tract epithelium (fig 3I, J) and in the vertebra, where the expression was restricted to the undifferentiated mesenchyme (data not shown). Interestingly, a weak signal was detected in a restricted area of the heart, at the apex of the interventricular septum (fig 3I, J). By day 47, MIDI expression increased in telencephalic vesicles and was also observed in the lateral part of the ventral diencephalon (fig 3O, P), the rhombencephalon (mainly in the cerebellar bud, fig $3 \mathrm{~K}, \mathrm{~N}$ ), the neurosensorial retina (fig $3 \mathrm{~K}, \mathrm{~L}$ ), the spinal cord (fig $3 \mathrm{Q}, \mathrm{R}$ ), and the dorsal root ganglia (fig 3S, T). Meanwhile, signal intensity decreased in the mesencephalon (fig $3 \mathrm{M}, \mathrm{N}$ ). A strong expression was observed in the epithelia of nasal (fig $3 \mathrm{~K}-\mathrm{N}$ ), oral and oesophago-laryngeal cavities (fig 3K, L), the medial part of the tongue (fig $3 \mathrm{~K}, \mathrm{~L}$ ) but not laterally (fig $3 \mathrm{M}, \mathrm{N}$ ), in the respiratory and digestive tract epithelium (fig $3 \mathrm{Q}, \mathrm{R}$ ), the metanephros (fig $3 \mathrm{Q}, \mathrm{R}$ ), and in the anal folds (fig $3 \mathrm{U}, \mathrm{V}$ ). MIDI expression was also detected in myoblasts but not in forming bones or nerves (fig 3S, T). Finally, at 8.5 weeks of development, expression of the MIDl gene in the heart was still restricted to a small area of the interventricular septum (fig $3 \mathrm{~W}-\mathrm{Y}$ ).

\section{DISCUSSION}

Here we report on six MIDI mutations in a series of 14 Opitz syndrome patients including five familial forms and one sporadic case. All mutations identified in our series were novel mutations except the R495X mutation, which was previously reported in three unrelated patients. ${ }^{11} 18$ The mutations were truncating mutations (4), an in frame $9 \mathrm{bp}$ deletion and a missense mutation. They were scattered along the coding sequence, but most of them were located at the C-terminal end of the protein, either in the FNIII or the C-terminal domain. Our data support the prevalence of truncating mutations, as most cases resulted in frameshift mutations. Our study also supports the high mutation detection rate in familial forms of the disease. ${ }^{12} 18$

As far as genotype/phenotype correlations are concerned, it is striking to note that $4 / 5$ patients carrying the $\mathrm{R} 495 \mathrm{X}$ mutation had a cerebellar anomaly (family 6, two cases in the present report, one patient reported by Cox et $\mathrm{al}^{18}$ and two by De Falco et $\left.\mathrm{al}^{11}\right)$. Vermis hypoplasia or agenesis was also present in two other patients of our series, who carried a R277X and a 1047-1448insAACA mutation, respectively. Interestingly, no developmental delay was noted in the patient carrying the 1047-1448insAACA mutation. Finally, two other cerebral anomalies were described in two patients: a corpus callosum agenesis $\left(1312 \mathrm{delATG}^{7}\right)$, and a Dandy-

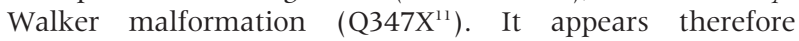
that vermis hypoplasia or agenesis was the most common brain anomaly in Opitz syndrome patients with MIDI mutations, particularly in association with the R495X mutation $(\mathrm{p}<<0.0001)$. Therefore, systematic brain exploration should be performed in patients with Opitz syndrome even in the absence of mental retardation. On the other hand, no other phenotype/genotype correlation could be established in patients carrying a MIDI mutation. In particular, no relationship was observed between the location of the mutation and the severity of the disease..$^{711} 1218$

The role of MIDI during embryonic development has been investigated through expression studies conducted in mouse $^{19}$ and chicken. ${ }^{20}$ The murine Midl gene is nearly ubiquitously expressed but mostly in undifferentiated cells of the central nervous system, the developing branchial arches, and the gastrointestinal and urogenital systems. The developmental expression of chicken and mouse is very similar, a feature consistent with the strong homology observed between MIDI orthologues. However, at variance with chick, no heart expression of Midl was observed in the mouse. ${ }^{20}$ The present study shows that MIDI expression during human development correlates with organ involvement in Opitz syndrome, namely a defect in closure of the facial and pharyngeal processes (oronasal clefts and tracheo-oesophagal fistulas) and fusion defect of urethral folds (hypospadias). Moreover, the restriction of MIDI expression to heart interventricular septum correlates with conotruncal lesions commonly seen in Opitz syndrome. Consistently, 30\% of the 39 MIDI mutated patients reported so far presented a congenital heart defect. ${ }^{7112182122}$ MIDI is also expressed in the cerebellum bud, correlating with cerebellar involvement in Opitz syndrome (vermis hypoplasia or agenesis). Based on this study, we suggest that cardiac defects and cerebellar anomalies belong to the Opitz syndrome spectrum.

Despite the skewed pattern of $\mathrm{X}$-inactivation found in a female patient with Opitz syndrome, strongly suggesting an X-linked disease, no MIDl mutation was identified in this patient by sequencing the whole MIDI coding sequence. We may have failed to find a MIDI genomic duplica$\operatorname{tion}^{711} 12182122$ or non-coding sequence alterations. On the other hand, this could suggest another X-linked Opitz gene. Finally, considering that three obligate carrier mothers showed a random pattern of $\mathrm{X}$-inactivation, it appears that $\mathrm{X}$-inactivation studies in females do not help when discriminating the X-linked form of the disease.

In conclusion, the present study contributes to further delineate the molecular spectrum underlying the Opitz syndrome phenotype. Furthermore, expression studies during 
early human development strongly suggest that MIDI is involved in human heart development, and also support the view that vermis hypoplasia or agenesis should be regarded as an important clinical feature of Opitz syndrome.

\section{ACKNOWLEDGEMENTS}

We thank all the clinicians for sending us patient material: Y Alembick, V Cormier-Daire, L Faivre, B Gilbert, A Goldenberg, P Jonveau, and J Martinovic.

\section{Authors' affiliations \\ L Pinson, J Augé, S Audollent, G Mattéi, H Etchevers, N Gigarel, F Razavi, M Le Merrer, J Amiel, A Munnich, S Lyonnet, M Vekemans, T Attié-Bitach, Département de Génétique et Unité INSERM U-393, Hôpital Necker-Enfants Malades, Paris, France}

D Lacombe, Service de Génétique Médicale, Hôpital Pellegrin Enfants, Bordeaux, France

S Odent, Service de Génétique Médicale, Hôpital Pontchaillou, Rennes, France

G Meroni, Telethon Institute of Genetics and Medicine, Naples, Italy LP was granted a fellowship from la Fondation pour la Recherche Médicale (FRM). This work was supported by EURExpress and HMR (Hoechst-Marion-Roussel) grants.

Conflicts of interest: none declared.

Correspondence to: T Attié-Bitach, Département de Génétique et Unité INSERM U-393, Hôpital Necker-Enfants Malades, Paris, France; tania. attie@necker.fr

Received 23 September 2003

Accepted for publication 4 December 2003

\section{REFERENCES}

1 Opitz J, Frias J, Gutenberg J, et al. The G syndrome of multiple congenital anomalies. Birth Defects 1969;2:95-101.

2 MacDonald MR, Schaefer GB, Olney AH, Tamayo M, Frias JL. Brain magnetic resonance imaging findings in the Opitz $G / B B B$ syndrome: extension of the spectrum of midline brain anomalies. Am J Med Genet 1993;46:706-11.

3 Gorlin R, Cohen M, Hennekam R. Opitz oculo-genito-laryngeal syndrome (Opitz BBB/G compound syndrome). In: Syndromes of the head and neck. Vol 19. Oxford: Oxford University Press, 2001:988-91.

4 Robin NH, Feldman GJ, Aronson AL, Mitchell HF, Weksberg R, Leonard CO, Burton BK, Josephson KD, Laxova R, Aleck KA. Opitz syndrome is genetically heterogeneous, with one locus on Xp22, and a second locus on 22q11.2. Nat Genet 1995:11:459-61

5 Fryburg JS, Lin KY, Golden WL. Chromosome 22q11.2 deletion in a boy with Opitz (G/BBB) syndrome. Am J Med Genet 1996;62:274-5.

6 McDonald-McGinn DM, Emanuel BS, Zackai EH. Autosomal dominant "Opitz" GBBB syndrome due to a 22q11.2 deletion. Am J Med Genet 1996:64:525-6.

7 Quaderi NA, Schweiger S, Gaudenz K, Franco B, Rugarli El, Berger W, Feldman GJ, Volta M, Andolfi G, Gilgenkrantz S, Marion RW, Hennekam RC,
Opitz JM, Muenke M, Ropers HH, Ballabio A. Opitz G/BBB syndrome, a defect of midline development, is due to mutations in a new RING finger gene on Xp22. Nat Genet 1997;17:285-91.

8 Schweiger S, Foerster J, Lehmann T, Suckow V, Muller YA, Walter G, Davies T, Porter $\mathrm{H}$, van Bokhoven $\mathrm{H}$, Lunt PW, Traub P, Ropers HH. The Opitz syndrome gene product, MID1, associates with microtubules. Proc Natl Acad Sci U S A 1999;96:2794-9

9 Cainarca S, Messali S, Ballabio A, Meroni G. Functional characterization of the Opitz syndrome gene product (midin): evidence for homodimerization and association with microtubules throughout the cell cycle. Hum Mol Genet 1999;8:1387-96.

10 Trockenbacher A, Suckow V, Foerster J, Winter J, Krauss S, Ropers HH, Schneider R, Schweiger S. MIDI, mutated in Opitz syndrome, encodes an ubiquitin ligase that targets phosphatase 2A for degradation. Nat Genet 2001;29:287-94.

11 De Falco F, Cainarca S, Andolfi G, Ferrentino R, Berti C, Rodriguez Criado G Rittinger O, Dennis N, Odent S, Rastogi A, Liebelt J, Chitayat D, Winter R, Jawanda H, Ballabio A, Franco B, Meroni G. X-linked Opitz syndrome: novel mutations in the MIDI gene and redefinition of the clinical spectrum. Am J Med Genet 2003:120A:222-8.

12 Gaudenz K, Roessler E, Quaderi N, Franco B, Feldman G, Gasser DL, Wittwer B, Horst J, Montini E, Opitz JM, Ballabio A, Muenke M. Opitz G/BBB syndrome in Xp22: mutations in the MIDI gene cluster in the carboxy-terminal domain. Am J Hum Genet 1998:63:703-10.

13 Benit P, Kara-Mostefa A, Berthelon M, Sengmany K, Munnich A, Bonnefont JP. Mutation analysis of the hamartin gene using denaturing high performance liquid chromatography. Hum Mutat 2000;16:417-21.

14 Hickey T, Chandy A, Norman RJ. The androgen receptor CAG repeat polymorphism and X-chromosome inactivation in Australian Caucasian women with infertility related to polycystic ovary syndrome. J Clin Endocrinol Metab 2002;87:161-5.

15 Wilkinson DG. In situ hibridization: a practical approach, 2nd ed. Oxford: Oxford University Press, 1999.

16 Liu J, Prickett TD, Elliott E, Meroni G, Brautigan DL. Phosphorylation and microtubule association of the Opitz syndrome protein mid- 1 is regulated by protein phosphatase $2 \mathrm{~A}$ via binding to the regulatory subunit alpha 4 . Proc Natl Acad Sci U S A 2001;98:6650-5.

17 Short KM, Hopwood B, Yi Z, Cox Tc. MID1 and MID2 homo- and heterodimerise to tether the rapamycin- sensitive PP2A regulatory subunit, $\alpha 4$ to microtubules: implications for the clinical variability of X-linked Opitz GBBB syndrome and other developmental disorders. BMC Cell Biol 2002;3:1.

18 Cox TC, Allen LR, Cox LL, Hopwood B, Goodwin B, Haan E, Suthers GK. New mutations in MIDI provide support for loss of function as the cause of $X$-linked Opitz syndrome. Hum Mol Genet 2000;9:2553-62.

19 Dal Zotto L, Quaderi NA, Elliott R, Lingerfelter PA, Carrel L, Valsecchi V, Montini E, Yen CH, Chapman V, Kalcheva I, Arrigo G, Zuffardi O, Thomas S, Willard HF, Ballabio A, Disteche CM, Rugarli El. The mouse Midl gene: implications for the pathogenesis of Opitz syndrome and the evolution of the mammalian pseudoautosomal region. Hum Mol Genet 1998;7:489-99.

20 Richman JM, Fu KK, Cox LL, Sibbons JP, Cox TC. Isolation and characterisation of the chick orthologue of the Opitz syndrome gene, Midl, supports a conserved role in vertebrate development. Int J Dev Biol 2002;46:441-8

21 Winter J, Lehmann T, Suckow V, Kijas Z, Kulozik A, Kalscheuer V, Hamel B, Devriendt K, Opitz J, Lenzner S, Ropers HH, Schweiger S. Duplication of the MIDI first exon in a patient with Opitz G/BBB syndrome. Hum Genet 2003;112:249-54

22 Schweiger S, Schneider R. The MID1/PP2A complex: a key to the pathogenesis of Opitz BBB/G syndrome. Bioessays 2003;25:356-66. 